\title{
EDITORIAL
}

\section{Reflections on the Past and Future of Integrative Medicine from a Lifelong Student of the Integration of Chinese and Western Medicine}

\author{
David Eisenberg, M.D.*
}

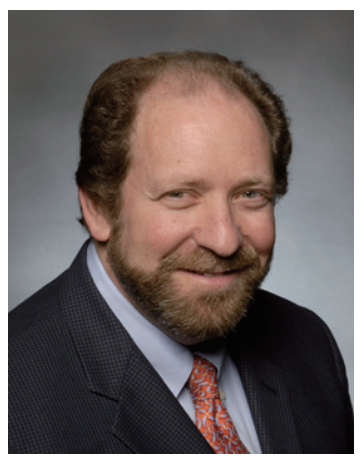

This issue of the Chinese Journal of Integrative Medicine includes a discussion of integrative medicine (IM) from various perspectives. Dr. Andrew Weil provides a comprehensive overview of the field from the US and Western perspectives $^{(1)}$; doctors Dobos and $\mathrm{Tao}^{(2)}$ delineate those aspects of Western IM which relate directly to Traditional Chinese Medicine (TCM); doctors Lee, Shin, et $\mathrm{al}^{(3)}$ provide a systematic review of controlled trials of IM from the Korean literature; and Dr. Robinson contrasts IM in the West (United Kingdom) with IM in China ${ }^{(4)}$. Importantly, each of these articles highlights the extraordinary relevance of TCM to emerging models of "IM" worldwide.

Allow me to add some additional reflections based on my own exploration of TCM over the years.

Forty years ago this July, I was a 16-year-old high school student in New York reading the daily New York Times. An article appeared on the front page entitled, "Now let me tell you about my appendectomy in Peking". The author, James Reston, told the incredible story of his having traveled to Beijing in 1971, coincident with Henry Kissinger's then secretive discussions with the Chinese leadership to reestablish political relations between the US and China. As fate would have it, Reston developed acute abdominal pain, was rushed to the prestigious Peking Union Medical College (PUMC) Hospital and diagnosed with acute appendicitis. After having his appendix successfully removed, Reston experienced two days of severe, persistent abdominal pain. A PUMC staff acupuncturist, representing a professional group unheard of at that time in the West, was summoned and permitted to place thin needles in Reston's right elbow and below both knees. This "acupuncture treatment", according to Reston, resulted in the total relief of his symptoms within one hour. This provocative claim by a highly credible Western correspondent was read all over the world. In hindsight, that article changed my life and sent me on a curious 40 years professional odyssey. By extension, Reston's article contributed to the evolution of "IM" worldwide.
My fascination with Reston's story was on my mind as I entered Harvard College in 1972. As part of an independent study on TCM I discovered a translation of the famous "Yellow Emperor's Classic on Internal Medicine", written circa 400 BCE and translated by Ilza Veith $^{(5)}$. Two quotations, each critically central to the fundamental principles of TCM captivated me. The first spoke of the superiority of prevention over intervention: "To administer medicines to diseases which have already developed and thereby suppress bodily chaos which has already occurred is comparable to the behavior of those who would begin to dig a well after they have already grown thirsty or those who would begin to test weapons after they have engaged in battle. Would these actions not be too late?"

The second quote read as follows: "I have heard that in early times the people lived to be over 100 years old. But these days people only reach half that age and must curtail their activities. Does the world change from generation to generation or does man become negligent of the laws of nature?... Today people do not know how to find contentment within. They are not skilled in the control of their (psychological/emotional) spirits. For these reasons they reach only half of their 100 years and they degenerate."

In 1972, the Western biomedical community was making great strides with regard to the mechanistic study of disease and the discovery of novel therapeutic interventions for conditions that have caused human suffering for millennia. A prioritized discussion on the role of prevention and lifestyle choices, such as the optimization of diet, the need for movement and the complex relationship between mind and body were not central to my premedical education nor were they priority topics within university curricula. Nonetheless, I was drawn to these concepts like a child is drawn to sparkling

CThe Chinese Journal of Integrated Traditional and Western Medicine Press and Springer-Verlag Berlin Heidelberg 2011

*Director of Osher Research Center, Division for Research and Education in Complementary and Integrative Medical Therapies, Harvard Medical School, USA; Honorary Professor of the Beijing University of Chinese Medicine

Tel: 001-617-384-8550, Fax: 001-617-384-8555, E-mail: david_eisenberg@hms.harvard.edu

DOI: 10.1007/s11655-011-0622-5 
objects. The "Treasure House of TCM" as Chairman Mao called it, had been unveiled to me and to the larger (and skeptical) Western medical establishment.

I learned Mandarin Chinese at Harvard University and in 1979 was sent by the US National Academy of Sciences to serve as the first US medical exchange student to the People's Republic of China. For much of 1979-1980 I lived in Beijing along with several other young doctors in training from Europe and Africa. We resided in a 400-year old "hu-tong" and studied TCM theory and practice at the Beijing Institute of TCM and Dongzhimen Hospital. What I saw there impressed me deeply. While not uniformly successful, on several occasions, herbal therapies, acupuncture, Tai Chi, massage, manipulations of bones and various forms of meditation all appeared to benefit selected patients whom I followed closely in both inpatient and outpatient settings. I observed that acupuncture anesthesia was successful even in several patients who did not believe it would work. I personally interviewed these patients and monitored them physiologically during surgical procedures. I was left wondering, how did these therapies work when they worked? Was it necessary to believe in them and, if so, to what extent could belief (or "context" or "placebo") increase or decrease the effectiveness of any given therapy, TCM or Western medicine for that matter? Could some of these specific TCM based approaches be exported to the West and successfully incorporated into a combined "integrative" model of care for specific patient populations? What could Western scientists and clinicians learn from TCM and vice versa? Would my University and others like it be receptive to this line of inquiry or would their senior faculty reflexively view such an effort as advocacy work propelled by bias, naivety and backward thinking?

What strategy, I wondered, would lead most effectively to the rigorous scientific evaluation of these TCM approaches? Like many new fields, a description of the prevalence, patterns of use and costs of these therapies was a logical first step. This approach led to the implementation of US national surveys published in the New England Journal of Medicine ${ }^{(6)}$ and JAMA ${ }^{(7)}$, documenting that a third or more of adults routinely use complementary therapies; make hundreds of millions of office visits per year; and, spend tens of billions of dollars out-of-pocket on these complementary therapies. The most recent US national survey performed by the US Centers for Disease Control ${ }^{(8)}$ concluded that $38 \%$ of adults and $12 \%$ of children routinely use CAM therapies to treat their most serious medical conditions, make more than 350 million office visits to CAM providers annually, and spend more than $\$ 34$ billion out of pocket. This amount represents $11 \%$ of all out-of-pocket expenditures on health care in the US annually. Comparable national surveys have been conducted worldwide and have observed similar patterns.

However, prevalence statistics do not establish evidence of efficacy, professional uniformity or competency nor do they provide any information about plausible mechanisms of action, reproducibility, safety and cost effectiveness. These necessary prerequisites to scientific acceptance have been the focus of researchers worldwide for the past two decades. The US national Center for Complementary and Alternative Medicine (NCCAM) established in 1992 currently spends \$123 million per year on CAM related research. Across all $\mathrm{NIH}$ institutes and centers, the US government now spends in excess of $\$ 500$ million per year on research in this area. Importantly, NCCAM has recently released its five-year strategic plan for 2000-2014. Included in the plan is the objective to "Increase understanding of real-world patterns and outcomes of CAM use and its integration into healthcare and health promotion." This clearly stated intention sets the stage for the next phase in the development of IM. More specifically, it liberates researchers to venture beyond the pre-clinical (basic science) or clinical evaluation of single CAM (or TCM) therapies in order to test the hypothesis that coordinated access to both CAM (or TCM) and conventional therapies (paralleling coordinated access to both Eastern and Western medicine) may result in superior clinical outcomes and reduced overall cost of treatment for selected patient populations. Such experiments, if thoughtfully planned and executed could, if positive, attract the attention of skeptical scientists, clinicians, educators and health policy makers worldwide.

The stage is now set for the next generation of young investigators interested in the "integration of Chinese and Western medicine" and the development of evidence-based, patient centered participatory and financially sustainable models of care to make their contributions. The international scientific community is now investing in areas no one would have thought possible in 1971 when James Reston wrote his famous article. The US and European Union now support a range of research initiatives aimed at more fundamental questions of mechanism. For example how does acupuncture affect the nervous system and connective tissue? How do context, belief, conditioning and placebos alter the brain, central and peripheral nervous systems? How do specific compounds within traditional Chinese medicinal herbs work individually and in complex mixtures? How does Tai Chi (and Yoga) predictably affect physiologic mechanisms and how can these be applied to multiple common disease populations? Increasingly, there is also a growing fascination with the question of how lifestyle choices 
(e.g. nutrition and diet, exercise and movement, stress management and meditative techniques) alter genetic regulation. These investigations address the fundamental question as to whether lifestyle choices can decrease the risk of disease in individuals who carry particular genes. This research in genetics and epigenetics may be the meeting place between modern and ancient medicines, Eastern and Western medicine, conventional and integrative medicine in the coming decades.

There is also now the prospect of moving beyond mechanistic and reductionistic studies each of which has the potential to offer disruptive scientific innovation, in order to simultaneously move to the realm of costeffectiveness research. Only recently have large scale studies been envisioned and implemented to test the idea that coordinated access to both conventional and CAM therapies (or coordinated access to both Eastern and Western medicine) may result in superior clinical outcomes at a reduced overall cost when compared to access to usual care alone. Might this combined approach be useful to prevent, treat and manage back pain? Obesity? Diabetes? Specific types of cancer?

Importantly, there is now a much greater willingness on the part of investigators throughout the international community to work more closely across national boundaries on both preclinical as well as clinical studies of complementary and integrative medicine. By way of example, a soon-to-be published article summarizes the work of dozens of US and Chinese co-investigators who have jointly established a library of authenticated traditional Chinese medicinal plants to be systematically evaluated using state of the science technologies ${ }^{(9)}$. No one could possibly have imagined such an ambitious, multi-disciplinary, international collaboration 30, 20 or even 10 years ago.

TCM theory teaches that "qi governs the body", "the Will governs the qi" and "Intention governs the Will." While we continue to focus our human and financial resources on studies to explore the safety, mechanism, efficacy and cost-effectiveness of complementary and integrative medical therapies, let us never forget our shared intention, namely to jointly develop new models of comprehensive health care, drawing on therapies of both Eastern and Western origin, to maximally prevent, treat and manage disease and suffering. This research must not be viewed as a competition nor as a way to "prove" pre-existing claims, but rather as a means of learning from and with each other. Collectively, we can and will make discoveries of great consequence.

To those young investigators courageous enough to consider serving as the next-generation of scouts and pioneers in the "Integration of Chinese and Western Medicine" know that we are enlarged by people and approaches different from ours. Our differences are to be shared and celebrated not feared or dismissed.

A Chinese proverb says "The methods used by one may be faulty. Those used by many will be better." And finally there is the notion that "Real gold fears not the heat of the hottest fire." Those aspects of Chinese medicine, complementary medicine, IM and the Integration of Chinese and Western Medicine which can be proven to be reproducible, safe, and effective with plausible mechanisms of action will point the way to a more integrative, multidisciplinary, comprehensive health care delivery model for future generations.

As such, the future of IM remains bright as we look forward to the next 40 years of its evolution worldwide.

\section{REFERENCES}

1. Weil A. The state of the integrative medicine in the U.S. and Western world. Chin J Integr Med 2011; 17:6-10.

2. Dobos G, Tao I. The model of Western integrative medicine: the role of Chinese medicine. Chin J Integr Med 2011;17:11-20.

3. Lee MS, Shi B, Choi T, Kim J. Randomized clinical trials on Eastern-Western integrative medicine for health care in Korean literature: a systematic review. Chin J Integr Med 2011;17:48-51.

4. Robinson N. Integrative medicine - traditional Chinese medicine, a model? Chin J Integr Med 2011;17:21-25.

5. Mao SM, ed. Veith I, translate. The yellow emperor's classic of internal medicine. Boston: Shambhale Pulbications, Inc; 1995.

6. Eisenberg DM, Kessler RC, Foster C, Norlock FE, CalkinsDR, Delbanoc TL. Unconventional medicine in the United States. Prevalence, costs and patterns of use. NEJM 1993;328:246-252.

7. Eisenberg DM, Davis RB, Ettner SL, Appel S, Wilkey S, Van Rompay M, et al. Trends in alternative medicine use in the United States 1990-1997. Results of a Follow-up National Survey. JAMA 1998;280:1569-1575.

8. Nahin RL, Barnes PM, Stussman BJ, Bloom B. Costs of complementary and alternative medicine (CAM) and frequency of visits to CAM practitioners: United States, 2007. Natl Health Stat Report 2009:1-14.

9. Eisenberg DM, Harris ESJ, Littlefield BA, Shugeng $C$, Craycroft JA, Scholten R, Bayliss P, Fu Y, Wang W, Jiang QY, Zhao ZZ, Hubiao C, Liu Y, Kaptchuk T, Hahn WC, Wang X, Roberts T, Shamu CE, Clardy J. Developing a library of authenticated traditional Chinese medicine (TCM) plants for systematic Biological Evaluation - Rationale, methods and Preliminary results from a Sino-American collaboration. Fitoterapia (In press, January 2011).

(Received November 30, 2010) Edited by TAO Bo 